\title{
Larval stage controls on Pacific sardine recruitment variability: high zooplankton abundance linked to poor reproductive success
}

\author{
Vera N. Agostini ${ }^{13, *}$, Andrew Bakun ${ }^{2}$, Robert C. Francis ${ }^{1}$ \\ ${ }^{1}$ School of Aquatic and Fishery Sciences, University of Washington, Seattle, Washington 98195, USA \\ ${ }^{2}$ Pew Institute for Ocean Sciences, Rosenstiel School of Marine and Atmospheric Sciences, University of Miami, Miami, \\ Florida 33149, USA \\ ${ }^{3}$ Present address: Pew Institute for Ocean Sciences, Rosenstiel School of Marine and Atmospheric Sciences, \\ University of Miami, Miami, Florida 33149, USA
}

\begin{abstract}
Sardines inhabit some of the most highly productive areas of the ocean (upwelling areas). Despite this, those in the eastern Pacific appear to thrive during warm years characterized by low productivity. Among the explanations for the apparent sardine success during warm years are: (1) lowered predation pressure and (2) access to waters with higher food availability. We examine zooplankton abundance in the sardine Sardinops sagax larval habitat off the coast of southern California. According to our results, increased food availability (represented here by zooplankton abundance) cannot alone explain successful sardine year classes. It appears that zooplankton abundance may also be an index of predation pressure on larval stages, combining potential effects of (1) direct predation by zooplankton predators and (2) increased attraction of zooplanktivorus nekton. Accordingly, decreased predation pressure during warm years may be a major factor allowing bursts in sardine recruitment. These results suggest a need for modification of the traditional rather linear view of food web energy transfers. This view may neglect potential nonlinear feedbacks introduced in the food web by mortalities on the early life stages of higher trophic level organisms inflicted or mediated by lower trophic level organisms.
\end{abstract}

KEY WORDS: Predation · Recruitment $\cdot$ Sardine $\cdot$ Trophic control $\cdot$ Zooplankton Resale or republication not permitted without written consent of the publisher

\section{INTRODUCTION}

Trophic controls of fish populations have been widely described in the literature (reviewed in Cury et al. 2003). As a result, terminology like 'top-down', 'bottom-up' and 'wasp waist' is often loosely used in an attempt to describe dominant energy flows in marine ecosystems. Food web models often treat fish simply in terms of adult biomass. Considering multiple life-history stages, however, yields a more complex picture. A particular component of an ecosystem, for example, could be controlled by a number of mechanisms (topdown, bottom-up), each operating at a different lifehistory stage. In the present study, we use Pacific sar- dine Sardinops sagax as an example and show that considering the early life-history stages leads to a more complete view of the system where the mixture of controls is adequately represented.

Sardines (genera: Sardinops and Sardina) are a group of fishes that live in highly productive large marine ecosystems (LMEs): the coastal regions off Japan and the California, Humboldt, Benguela and Canary Current systems. Intensive sardine fisheries are conducted in these areas, and each of these fisheries faces extremely variable population sizes. Pacific sardine, for example, dominated the west coast fisheries of North America for much of the first half of the 20th century. The population collapsed in the late 


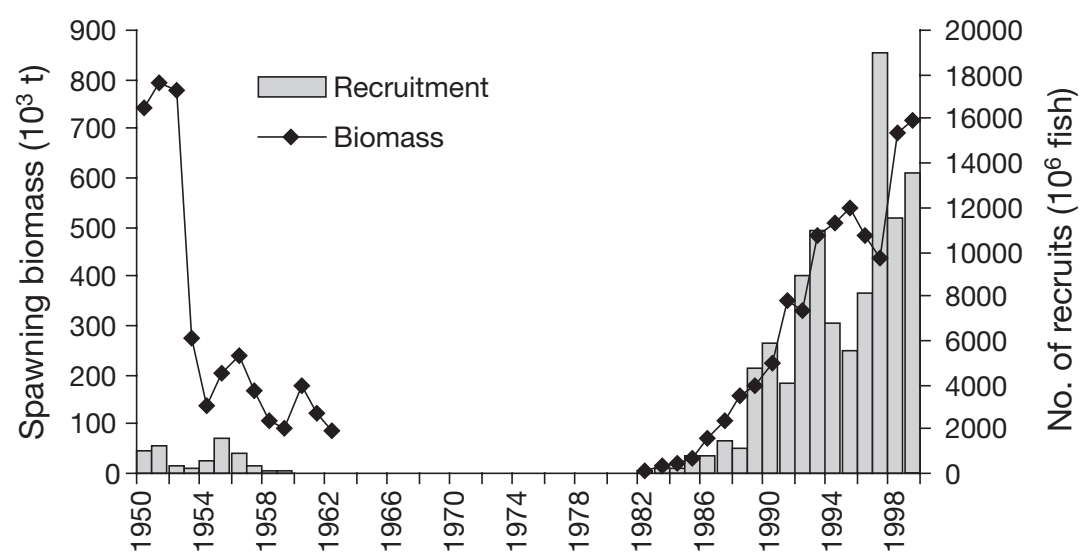

Fig. 1. Sardinops sagax. Time series of Pacific sardine recruits (numbers of Age 0 fish) and adult biomass (Age 1+)

That sampling program includes a large number of net tow samples, taken fairly regularly and continuously over multi-decadal time scales, from which total zooplankton volumes have been measured and tabulated.

Bakun \& Broad (2003) emphasize the role of the pervasive fields of predation faced by tiny organisms, such as fish larvae, in the ocean. These authors hypothesize that opportune gaps potentially opening on occasion in these predation fields may, in fact, lead to remarkable reproductive success of a number of fish populations around the globe. Thus, they explain the apparent success of Pacific sardine during warm years (El Niño) to be the

1940s, and remained at very low levels until the mid1980s, when it began to rebuild (Fig. 1).

Although sardines have adapted to inhabit highly productive areas (boundary currents), they reportedly thrive, at least in the eastern Pacific, during warm periods characterized by decreased primary productivity. Their reproductive success is reported to improve during warm years (e.g. El Niño) (Lluch-Belda et al. 1991, Jacobson \& MacCall 1995, Bakun \& Broad 2003), and population sizes have also generally increased during decadal periods of 'heightened El Niño character' (Bakun \& Broad 2003). In warm periods, the center of spawning has been reported to shift northward (Smith 1990, McFarlane et al. 2002), where spawning habitat characteristics during these times must evidently be more favorable compared to southern areas (e.g. temperature range, adult food availability). At least 2 hypotheses could potentially explain why sardine reproductive success improves when the reproductive habitat shifts northward: (1) larval food concentration increases and (2) larval predation pressure decreases. Food (faster growth, reduced starvation) and predation (lower predator incidence) are 2 habitat characteristics that potentially influence larval survival. While the effect of food availability on larval survival has been discussed at length (Hjort 1914, Lasker 1975), predation on fish eggs and larvae is 'one of the most critical, but least understood factors affecting the recruitment of marine fishes' (Hunter 1975)

Few data sets are available to empirically address these types of questions in a manner comprehensive enough to yield significant inferences with respect to net interannual consequences. Perhaps the longest regularly maintained time series of relevant observations covering a major portion of a regional habitat population is the CalCOFI (California Cooperative Oceanic Fisheries Investigations) data series (Fig. 2). result of decreased predation pressure on early lifehistory stages (i.e. low food concentrations characteristic of El Niño years are overcompensated by the reduced predation pressure on sardine larvae, possibly leading to a burst in recruitment). Planktonic invertebrates are among the wide variety of predators that feed on fish larvae. The effect of predation by planktonic invertebrates has been documented for a number of egg and larval populations of clupeoid fish (Bailey 1994). A number of authors, for example, have reported on predation by zooplankton on herring and

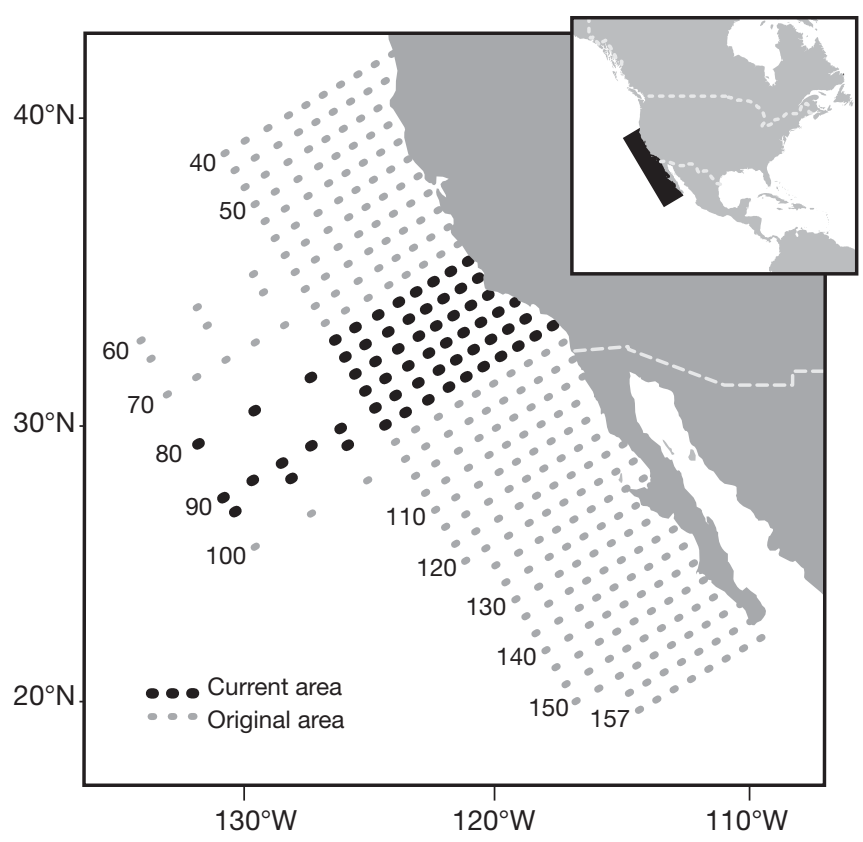

Fig. 2. Stations sampled by the CalCOFI program from 1948 to present. Black dots identify stations sampled consistently throughout the time period (see 'Data and methods' for explanation) 
anchovy (Smith \& Lasker 1978, Alvariño 1980, Purcell 1990, Theilacker et al. 1993). Little has been documented, however, concerning predation of planktonic invertebrates on small sardine larvae. Increased plankton abundance, in general, may also increase predation pressure on sardine larvae by attracting nektonic zooplanktivores (Pacific mackerel, etc.). These may consume fish eggs and larvae along with more abundant zooplanktonic prey, or may spawn voraciously predatory early life stages that may prey on sardine larvae.

Thus, variability in the CalCOFI zooplankton volume data set may be both an index of larval food for sardines (i.e. copepod nauplii and other suitable larval food items may be expected to be relatively abundant in situations where samples yield relatively high zooplankton volume) and an index of predation (due both to direct predation by zooplankton and to the potential of abundant zooplankton to attract zooplanktivores that may also prey, even preferentially if the opportunity presents itself, on fish larvae). However, the 2 effects act oppositely with respect to reproductive success, i.e. a positive relationship of annual recruitment to zooplankton abundance in the larval habitat of the year-class in question would indicate a predominant effect of food availability, while a negative (inverse) relationship would indicate predominance of predation over larval food availability in determining net annual reproductive success. A significant result one way or the other would yield important insight into the apparent paradox of improved reproductive success during warm years, which, on regional scales at least, are known to be characterized by reduced primary productivity in the eastern boundary regions of the Pacific (e.g. Barber \& Chavez 1983).

In the present study, we quantified the abundance of zooplankton in sardine larval habitat within the CalCOFI region, off the southwest coast of North America (Fig. 2) from 1951 to 1998. Our objective was to explore how zooplankton communities may influence larval survival and, ultimately, recruitment success of Pacific sardine.

\section{DATA AND METHODS}

The CalCOFI program, a coordinated physical and biological monitoring program, was established following the initial collapse of the sardine population in the 1940s; it is the source of zooplankton and temperature data used in this study. Our time series for this analysis is based on single tows taken at all stations within the CalCOFI sampling pattern (Fig. 2), representing 37852 samples from which mesozooplankton volume and sea-surface temperature values were extracted. Details of the CalCOFI methods for measuring mesozooplankton $(>505 \mu \mathrm{m})$ volume, a measure of zooplankton abundance, are described in Smith (1990). These data were adjusted for changes in gear type during the CalCOFI program following the procedure described in Ohman \& Smith (1995). In order to account for the potential effects of gaps in the geographic coverage of the sampling program over time, our analysis was conducted using just data from the current sampling grid (consistently covered from 1951 to 1998).

Since Pacific sardine Sardinops sagax (hereafter called California sardine) are reported to spawn in the California Current LME primarily between February and August in 13.5 to $16.5^{\circ} \mathrm{C}$ water (Ahlstrom 1965, Parrish et al. 1989, Lluch-Belda et al. 1991, Bentley et al. 1996), sardine reproductive habitat (which we equate here to sardine larval habitat) for the stock in question was defined as limited to this temperature band within these months, and only samples falling within these criteria were used in the tests. Note that choosing a specific temperature window in this way to determine which samples will be incorporated into the analysis enables the analysis to automatically allow for spatial movement of the spawning zone that may have occurred in response to changes in sea temperatures brought about by interannual-scale climatic events such as El Niño, etc.

In order to gauge the possibility that the choice of sampling band specifics might significantly change the results, additional tests using slightly different reasonable choices of both seasonal and temperature windows (e.g. January to May, 13 to $17^{\circ} \mathrm{C}$ ) were also performed and generated similar results. Both laboratory and field observations report temperatures $>13^{\circ} \mathrm{C}$ to be suitable for sardine egg and larval survival (Lasker 1964, Smith 1978, Parrish et al. 1989, Bentley et al. 1996). The upper limit of spawning is less clear, but hovers around $16^{\circ} \mathrm{C}$ for the California sardine stock (Lluch-Belda et al. 1991). Wider windows would probably be required for other sardine stocks because, for example, Pacific sardine in southern stocks off southern Baja California spawn at higher temperature, with eggs and larvae found in waters up to $25^{\circ} \mathrm{C}$ (LluchBelda et al. 1991, Lynn 2003). It was found that the results remain quite robust to different choices of the sample selection criteria. Zooplankton abundances from tows falling within the selected seasonal and temperature window were extracted from the data set, and yearly average values were computed for the years where recruitment estimates were available. These data were regressed against sardine recruitment (number of Age 0 fish) and recruitment/spawner biomass (Age 0 fish [tons] $\times 10^{3} /$ Age $1+$ fish). Recruitment and spawner biomass time series were taken from 
Jacobson \& MacCall (1995) for the period from 1952 to 1961, and from Conser et al. (2003) for the period from 1983 to 1998 (Table 1). Reliable estimates of recruitment and spawner biomass for the period from 1960 to 1984 do not exist (Barnes et al. 1992). Zooplankton abundances were summarized for years of high (number of recruits $>5$ billion) and low recruitment (number of recruits $<5$ billion), as well as El Niño (EN), La Niña (LN) and neutral years. EN, LN and neutral years were assigned as outlined in Table 1, based on the winter classification (January, February and March) for the Niño 3.4 region $\left(5.5^{\circ} \mathrm{N}\right.$ to $5.5^{\circ} \mathrm{S}, 120$ to $\left.170^{\circ} \mathrm{W}\right)$ reported by the Center for Climate Prediction (www. ncep.noaa.gov).

Table 1. Sardinops sagax. Historical spawning biomass for 1952 to 1961 is sardine Age 2+ (Jacobson \& MacCall 1995). Recent spawning biomass for 1983 to 1998 is sardine Age 1+ (Conser et al. 2003). Recruitment is the number of Age 0 (millions) fish. Recruitment estimates from the first period (1952 to 1961) are numbers of fish (original values by Jacobson \& MacCall 1995 lagged by 2 yr). Recent recruitment estimates (1983 to 1998) are numbers of fish (Conser et al. 2003). Reliable spawning biomass and recruitment estimates for sardine from 1964 to 1982 are not available (Barnes et al. 1992). ENSO (El Niño-Southern Oscillation) year classification based on winter (January, February, March) Niño 3.4 index as reported by the center for climate prediction (www.ncep.noaa.gov). 0: neutral years; +: El Niño years; -: La Niña years

\begin{tabular}{|ccrcc|}
\hline Year & $\begin{array}{c}\text { Spawning } \\
\text { biomass } \\
\left(10^{3} \mathrm{t}\right)\end{array}$ & $\begin{array}{c}\text { No. of } \\
\text { recruits } \\
\left(10^{6} \text { fish }\right)\end{array}$ & $\begin{array}{c}\text { ln (zooplankton) } \\
\text { volume } \\
\left(\mathrm{ml} \mathrm{m}^{-3}\right)\end{array}$ & ENSO \\
\hline 1952 & 793 & 1197 & & 0 \\
1953 & 780 & 382 & 5.11 & 0 \\
1954 & 277 & 264 & 4.70 & 0 \\
1955 & 136 & 588 & 5.02 & - \\
1956 & 202 & 1586 & 5.24 & - \\
1957 & 239 & 905 & 5.67 & 0 \\
1958 & 170 & 288 & 4.54 & + \\
1959 & 108 & 111 & 4.22 & 0 \\
1960 & 90 & 74 & 4.64 & 0 \\
1961 & 177 & 56 & 4.26 & 0 \\
1983 & 5 & 141 & 4.06 & + \\
1984 & 13 & 226 & 4.64 & 0 \\
1985 & 21 & 220 & 5.29 & - \\
1986 & 30 & 846 & 4.11 & 0 \\
1987 & 74 & 832 & 4.34 & + \\
1988 & 107 & 1461 & 4.42 & + \\
1989 & 162 & 1159 & 4.21 & - \\
1990 & 177 & 4710 & 4.05 & 0 \\
1991 & 226 & 5902 & 4.32 & 0 \\
1992 & 353 & 4105 & 3.79 & + \\
1993 & 335 & 8928 & 3.38 & 0 \\
1994 & 495 & 10907 & 3.86 & 0 \\
1995 & 508 & 6786 & 4.11 & + \\
1996 & 532 & 5566 & 4.52 & - \\
1997 & 483 & 8136 & 4.08 & 0 \\
1998 & 457 & 19022 & 3.06 & + \\
\hline & & & & \\
\hline
\end{tabular}

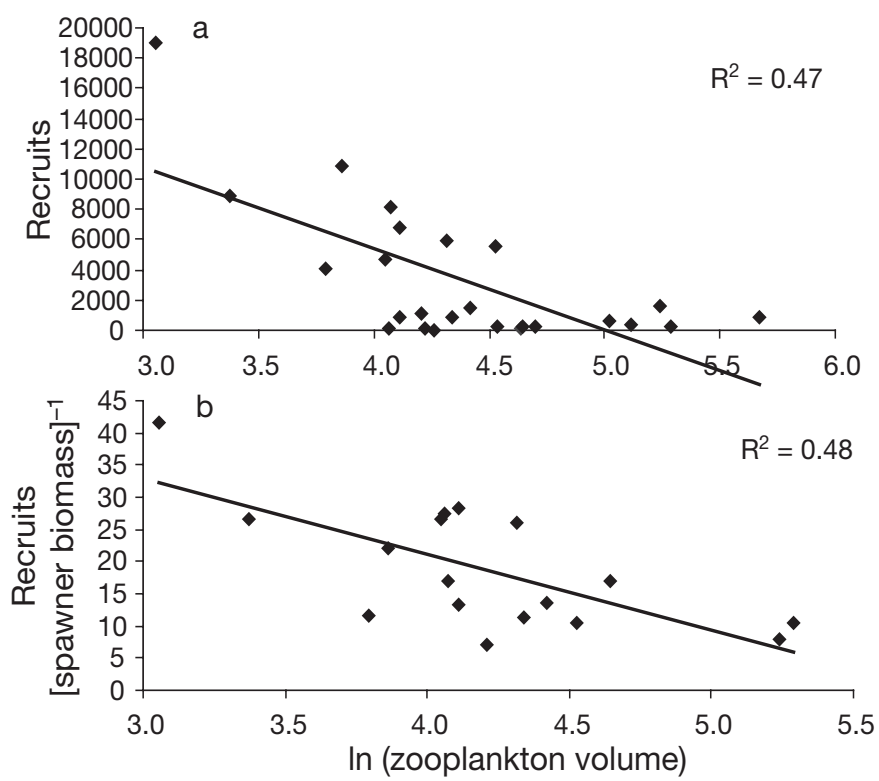

Fig. 3. Sardinops sagax. Log-linear relationship between (a) recruits (number of Age 0 fish $\times 10^{6}$ ) and zooplankton abundance $\left(\mathrm{ml} \mathrm{m}^{-3}\right)$ in preferred sardine spawning habitat; (b) recruits [spawner biomass] ${ }^{-1}$ and zooplankton abundance $\left(\mathrm{ml} \mathrm{m}^{-3}\right)$ in sardine-preferred spawning habitat (see 'Data and methods' for definition)

\section{RESULTS}

Our results indicate an inverse relationship between sardine recruitment and zooplankton abundance: recruitment decreases with increasing zooplankton abundance (recruits vs. $\ln$ [zooplankton volume], $\mathrm{r}^{2}=$ $0.47, F=27.47, \mathrm{df}=16$; recruits $\left[\right.$ spawner biomass ${ }^{-1}$ vs. $\ln \left[\right.$ zooplankton abundance], $\mathrm{r}^{2}=0.48, F=13.89$, df $=$ 16) (Fig. 3a,b). Mean zooplankton abundance in the relevant larval habitat zone is lower during high recruitment years $\left(48.52 \mathrm{ml} \mathrm{m}^{-3}\right)$, compared to the mean zooplankton abundance during low recruitment years $\left(91.83 \mathrm{ml} \mathrm{m}^{-3}\right.$ ) (Fig. 4, Table 2). Mean zooplankton abundance in the relevant zone was also lower during El Niño years $\left(49.90 \mathrm{ml} \mathrm{m}^{-3}\right)$ compared to the mean zooplankton abundance during La Niña years $\left(157.60 \mathrm{ml} \mathrm{m}^{-3}\right)$ and neutral years $\left(101.50 \mathrm{ml} \mathrm{m}^{-3}\right)$ (Fig. 5, Table 2). Differences in means between high and low recruitment years, as well as EN, LN and neutral years were tested using 2-sample $t$-tests (Table 2). All means reported above were significantly different $(\mathrm{p} \ll 0.05)$.

\section{DISCUSSION}

A central challenge in fisheries ecology is to understand the key processes influencing the survival of fish. 


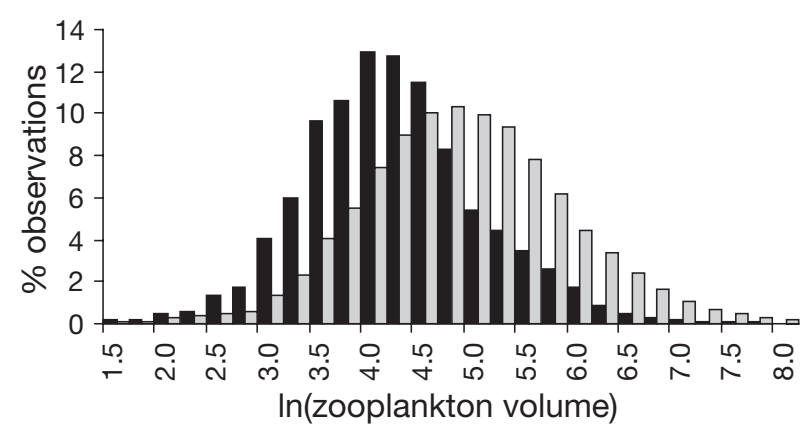

Fig. 4. Distribution of zooplankton volume $\left(\mathrm{ml} \mathrm{m}^{-3}\right)$ by observations in sardine-preferred spawning habitat (see 'Data and methods' for definition) during high-recruitment (black bars) and low-recruitment (gray bars) years

Most studies have focused on processes across lifehistory stages, and have rarely considered one mechanism to operate differently at different life-history stages. Zooplankton, for example, is often considered as a source of food, essentially a 'bottom up' forcing mechanism. For some species, zooplankton may be a source of both 'bottom up' and, 'top down' forcing, as it may be a predator of early life-history stages and prey to juvenile and adult stages.

Our study suggests that zooplankton abundance may, in fact, be an index of predation pressure on larval stages of California sardine Sardinops sagax, with decreased predation pressure during warm years being one of the factors allowing for bursts in sardine recruitment. Warm conditions have been known to displace the zone of favorable sardine habitat temperatures north (Smith 1990, McFarlane et al. 2002), possibly contributing to the observed sardine success during these periods. One hypothesis to explain this success is that the northern shift in sardine habitat allows access to waters richer in food concentrations, compared to southern waters occupied during colder periods (Baumgartner 2004). If this were the case, however, one would expect higher zooplankton abundances within the band of acceptable temperatures defining the sardine reproductive habitat during warm years, compared to the abundances found in that temperature band during cold years. This has not been

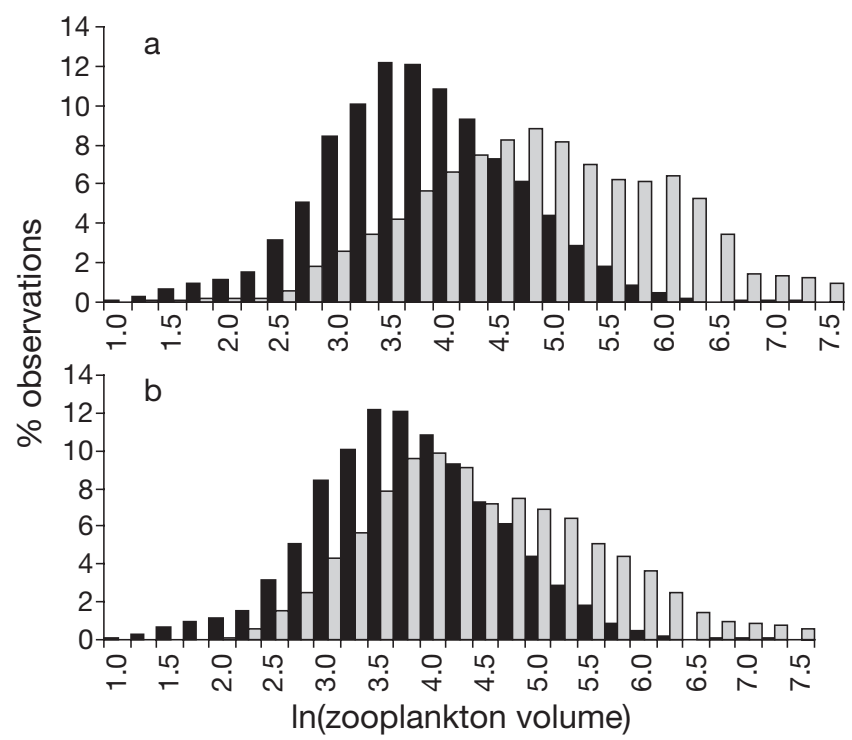

Fig. 5. Distribution of zooplankton volume $\left(\mathrm{ml} \mathrm{m}^{-3}\right)$ by observations in sardine-preferred spawning habitat during (a) El Niño years (black bars) and La Niña years (gray bars) and (b) El Niño years (black bars) and neutral years (gray bars)

found to be so. Our analysis shows that food abundances in the reproductive habitat of the California sardine are not elevated during periods of higher reproductive success. We find the mean abundance of zooplankton in sardine larval habitat to be lower during warm years and high recruitment years. This appears to support the 'loopholes' hypothesis formulated by Bakun \& Broad (2003), which essentially attributes enhanced sardine reproductive success during warm years to lowered predation pressure. In any event, our results show that reproductive success of California sardine cannot be explained by increased food availability in the larval habitat at the scale considered here.

Lynn (2003) reports high zooplankton biomass in sardine egg nursery areas during recent years. This suggests that adults choose areas in which to spawn that are rich in food concentrations (i.e. the adults appear to congregate where they can feed well, and spawn there in the process). However, reproductive success is

Table 2. Results of 2-sample $t$-tests for differences in mean zooplankton abundances (ln[zooplankton abundance] [ml $\left.\mathrm{m}^{-3}\right]$ ) during high and low recruitment (recr.) years, as well as El Niño (EN), La Niña (LN) and neutral years (see 'Data and methods' for definitions). $p$ : $p$-value (2-tail) for differences in means

\begin{tabular}{|lcrrr|}
\hline Group tested & Mean var. 1 & Mean var. 2 & df & p \\
\hline High recr. (var. 1) and low recr. (var. 2) & 48.42 & 91.83 & 1424 & $2.15 \times 10^{-43}$ \\
EN years (var. 1) and LN years (var. 2) & 49.9 & 157.60 & 475 & $1.94 \times 10^{-41}$ \\
EN years (var. 1) and neutral years (var. 2) & 49.9 & 101.50 & 615 & $2.59 \times 10^{-23}$ \\
\hline
\end{tabular}


determined by the survival rate of larvae and juveniles. While food availability is undoubtedly important to survival, our results point to the importance a release in predation pressure may have in determining the recruitment success of Pacific sardine. We believe that, as far as the effects on larval stages are concerned in determining net recruitment, the negative effect of increased predation could take precedence over the positive effect of increased food. This may not be surprising as the abundance of potential predators in the sea is much higher than the abundance of fish eggs and larvae (McGowan \& Miller 1980). Moreover, there is little evidence to support a contention that large numbers of larvae in the sea are starving (Sissenwine 1984).

Population growth of sardine has been shown to be sensitive to changes in vital rates of egg and early larval stages. Based on stage-based models, Lo et al. (1995) and Smith et al. (1992) show that the largest changes in sardine population growth come from a relative change in the mortality rate of egg and larval stages, concluding that mortality rates of these stages are the primary determinants of recruitment success. Reductions in mortality rates due to predation could occur during warm years and clearly have the potential to enhance recruitment success.

Superimposed on the interannual trends in zooplankton abundance we find here is a general decrease in zooplankton abundance observed in the California Current System over the past 50 yr (Roemmich \& McGowan 1995). A few authors have reported that the decrease in zooplankton is not uniform across species and that important patterns emerge when considering individual species (Rebstock 2001, Brinton \& Townsend 2003, Lavaniegos \& Ohman 2003). Lavaniegos \& Ohman (2003), for example, suggested that the decrease in zooplankton volume observed is primarily due to a decrease in abundance of tunicates (salps and doliolids). Many soft-bodied zooplankton have been known to consume fish eggs and larvae (reviewed in Alvariño 1980, Purcell 1990). Alvariño (1980) listed 109 potential planktonic predators found in CalCOFI samples collected in 1954, 1956 and 1958. She found an inverse relationship between abundance of anchovy larvae and abundance of siphonophores and medusae, as well as chaetognaths. In addition, anchovy larvae were never found in hauls dominated by pelagic prochordates (salps or pyrosomes). This leads us to believe that the decrease in tunicates described by Lavaniegos \& Ohman (2003) could represent a decrease in predation pressure on sardine eggs and larvae. Brinton \& Townsend (2003) found a decrease in euphasiid abundance during strong El Niño episodes, but no overall decrease during the last 50 yr. Theilacker et al. (1993) evaluated northern anchovy egg and larval mortality due to predation by the euphasiid assemblage commonly found in the California Current. Standardized CalCOFI plankton collections were analyzed to estimate prey and predator abundance and to apply an immunoassay technique to identify the predators. The authors confirmed that predation by euphausiids is a significant source of mortality (from 47 to $78 \%$ of total natural mortality) for the young stages of northern anchovy off California. Thus, the decrease in euphausiids reported by Brinton \& Townsend (2003) during strong El Niño episodes may also represent a decrease in predation pressure on California sardine eggs and larvae during those time periods.

Abrupt changes in zooplankton abundance have been observed to coincide with changes in sardine abundances in other areas of the world. In Peru, for example, the 1970s period of sardine increase occurred right after an abrupt collapse in zooplankton abundances (Carrasco \& Lozano 1989). The South African sardine collapsed during a period of greatly increasing zooplankton volume (Verheye 2000). It seems clear that if food availability were the dominant factor determining recruitment success, we would not be observing the same inverse relationship between zooplankton abundance and sardine recruitment in distant areas of the world.

The single measure of zooplankton abundance (settling volume) used in this study inseparably reflects both (1) abundance of potential food and (2) abundance of potential predators. One limitation is not having access to a time series of species composition that would allow us to (1) distinguish between the two and (2) investigate the potential effects of shifts in species composition such as the ones reported by McFarlane \& Beamish (2001). The information available on species composition over this time scale is limited, as the CalCOFI program does not systematically characterize the species composition of the zooplankton samples collected. Thus, we cannot exclude the possibility that lower zooplankton abundance during the 'high recruitment' years observed in the present study could simply be an indirect indicator of a change in plankton species composition. Sardine larvae might benefit from these shifts by suddenly gaining access to a preferred prey item. The trends observed by Lavaniegos \& Ohman (2003), however, do not support this, as they attributed the decrease in zooplankton to a decrease in tunicates, and not a change in the overall abundance of other species.

The other limitation is that, to the best of our knowledge, although the potential predatory role of planktonic invertebrates on sardine and other fish larvae has been discussed in the literature (McGowan \& Miller 1980), no studies to date exist on predation of zooplankton on sardine larvae. As a result we could only 
draw inferences based on studies conducted on other clupeoid species for which the effects of predation by planktonic invertebrates on a number of egg and larval populations have been documented (Smith \& Lasker 1978, Alvariño 1980, Purcell 1990, Theilacker et al. 1993). In order to fully evaluate the importance of zooplankton-related predation on Pacific sardine, zooplankton predation studies need to be extended to this species. The role that zooplankton may play in attracting other potential sardine predators should also be examined. Fish larvae are known to be prey to fish species such as Pacific mackerel Scomber japonicus, jack mackerel Trachurus symmetricus, etc. During years of high zooplankton abundance, these fish may copiously spawn, and their early life stages represent yet another source of predation on sardine larvae. In addition, there may be a greater attraction for these mobile wide-ranging pelagic species to enter the sardine reproductive zone, feed and incidentally spawn, during years when potential food (zooplankton) may be particularly abundant in that habitat zone.

In summary, we view habitat variability at larval stages as having an additive effect on reproductive success. In addition to predation, a number of other important factors potentially regulating sardine yearclass success exist (e.g. presence of alternative prey, rate of encounter, passive vs. active predation). For the sake of brevity we will not discuss them here. While a number of processes (both related to feeding/growth as well as predation) occurring at multiple life-history stages are undoubtedly important, our results indicate that the effect of predation at the larval stage is a factor powerful enough to emerge empirically from the confounding 'noise' related to other factors and mechanisms. Although not in the scope of this study, extending the understanding developed here for sardine to other clupeoid species such as anchovies may also allow us to understand what produces the alternating regimes of abundance that have long been documented in the California Current and in other upwelling systems of the world (Lluch-Belda et al. 1992).

The results of the present study emphasize the need for a comprehensive view of how trophic energy is transferred through an ecosystem. The conventional view that energy is transferred up the food web in a rather linear manner may not be entirely appropriate. Fish species are often modeled by representing trophic energy transfers among adult biomass, but population dynamics are, in many cases, determined at non-adult life-history stages. In the case of sardine, for example, what constitutes a predator during the larval stage (zooplankton) might later become prey during the adult stage. Taking into account earlier life stages and the potential non-linearities introduced into the food web by mortalities inflicted at these earlier levels offers a more complete view of the dynamics of the trophic systems in question.

Acknowledgements. We gratefully acknowledge the research vessel captains and crew as well as the many scientists participating in the CalCOFI program. In particular, we thank P. E. Smith and E. Logerwell for providing the data; K. M. Bailey, L. Ciannelli, R. Parrish, P. E. Smith and W. Wooster for useful discussion during the early parts of this study; and J. C. Field and A. B. Hollowed for critical review of this manuscript and valuable suggestions. This study was funded by the Joint Institute for the Study of the Atmosphere and Ocean (JISAO) under NOAA Cooperative Agreement No. NA17RJ1232 (Contribution No. 1328).

\section{LITERATURE CITED}

Ahlstrom EH (1965) A review of the effects of the environment on the Pacific sardine. ICNAF Spec Publ 6:53-76

Alvariño A (1980) The relation between the distribution of zooplankton predators and anchovy larvae. CalCOFI Rep 21:150-160

Bailey KM (1994) Predation on juvenile flatfish and recruitment variability. Neth J Sea Res 32(2):175-189

Bakun A, Broad K (2003) Environmental loopholes and fish population dynamics: comparative pattern recognition with focus on El Niño effects in the Pacific. Fish Oceanogr 12(4):1-16

Barber RT, Chavez FP (1983) Biological consequences of El Niño. Science 222:1203-1210

Barnes JT, Jacobson LD, MacCall AD, Wolf P (1992) Recent population trends and abundance estimates for sardine (Sardinops sagax). CalCOFI Rep 33:60-75

Baumgartner T, Guillermo A, Nakata H, Miller AJ (2004) Comparison of the effects of the 1976-1977 North Pacific climate shift on the California and Japanese sardine habitats. In: Abstracts volume, 13th annual meeting, North Pacific Marine Science Organization (PICES). North Pacific Marine Science Organization, Sidney

Bentley PJ, Emmett RL, Lo NCH, Moser HG (1996) Egg production of Pacific sardine (Sardinops sagax). CalCOFI Rep 37:193-200

Brinton E, Townsend A (2003) Decadal variability in abundances of the dominant euphausiids species in southern sectors of the California Current. Deep-Sea Res II 50: $2449-2472$

Carrasco S, Lozano O (1989) Seasonal and long-term variations of zooplankton volumes in the Peruvian Sea, 1964-1987. In: Pauly D, Muck P, Mendo J, Tsukayama I (eds) The Peruvian upwelling ecosystem: dynamics and interactions. ICLARM Conf Proc 18:82-85

Conser J, Hill KT, Crone PR, Lo NCH, Bergen D (2003) Stock assessment of Pacific sardine with management recommendations for 2003. In: Executive summary. Pacific Fishery Management Council, Rome

Cury P, Shannon L, Shin Y (2003) The functioning of marine ecosystems: a fisheries perspective. In: Sinclair M, Vladirmarsson G (eds) Responsible fisheries in the marine ecosystem. Food and Agriculture Organization, Rome, p 103-123

Hjort J (1914) Fluctuations in the great fisheries of northern Europe. Rapp Cons Int Explor Mer 20:1-13

Hunter JR (1975) Report of a colloquium on larval fish mortality studies and their relation to fisher research. US 
Department of Commerce, NOAA Tech Rep, NMFS Circ 395. National Marine Fisheries Service, Seattle, WA

Jacobson LD, MacCall AD (1995) Stock-recruitment models for Pacific sardine. Can J Fish Aquat Sci 52:566-577

Lasker R (1964) An experimental study of the effect of temperature on the incubation time, development, and growth of Pacific sardine embryos and larvae. Copeia 1964:399-406

Lasker R (1975) Field criteria for survival of anchovy larvae: the relation between inshore chlorophyll maximum layers and successful first feeding. Fish Bull (Wash DC) 73: $453-462$

Lavaniegos BE, Ohman MD (2003) Long-term changes in pelagic tunicates of the California Current. Deep-Sea Res Part II 50:2473-2498

Lluch-Belda D, Lluch-Cota DB, Hernandez Vasquez S, Salinas-Zavala CA (1991) Sardine and anchovy spawning as related to temperature and upwelling in the California Current system. CalCOFI Rep 31:105-111

Lluch-Belda D, Schwartzlose RA, Serra R, Parrish RH, Kawasaki T, Hedgecock D, Crawford RJM (1992) Sardine and anchovy regime fluctuations of abundance in four regions of the world oceans: a workshop report. Fish Oceanogr 1(4):339-347

Lo NCH, Smith PE, Butler JL (1995) Population growth of northern anchovy and Pacific sardine using stage-specific matrix models. Mar Ecol Prog Ser 127:15-26

Lynn RJ (2003) Variability in the spawning habitat of Pacific sardine (Sardinops sagax) off southern and central California. Fish Oceanogr 12(6):541-553

McFarlane GA, Beamish RJ (2001) The re-occurrence of sardines off British Columbia characterizes the dynamic nature of regimes. Prog Oceanogr 49:151-165

McFarlane GA, Smith PE, Baumgartner TR, Hunter JR (2002) Climate variability and Pacific sardine populations and fisheries. In: McGinn NA (ed) Fisheries in a changing climate. American Fisheries Society, Bethesda, MD, p 195-214

McGowan JA, Miller CB (1980) Larval fish and zooplankton

Editorial responsibility: Kenneth Sherman (Contributing

Editor), Narragansett, Rhode Island, USA community structure. CalCOFI Rep 21:29-36

Ohman MD, Smith PE (1995) A comparison of zooplankton sampling methods in the CalCOFI time series. CalCOFI Rep 36:153-158

Parrish RH, Serra R, Grant WS (1989) The monotypic sardines, sardina and sardinops: their taxonomy, distribution, stock structure and zoogeography. Can J Fish Aquat Sci 46(11):2019-2036

Purcell JE (1990) Soft-bodied zooplankton predators and competitors of larval herring (Clupea harengus pallasi) at herring spawning grounds in British Columbia. Can J Fish Aquat Sci 47:505-515

Rebstock GA (2001) Long term stability of species composition in calanoid copepods off southern California. Mar Ecol Prog Ser 215:213-224

Roemmich D, McGowan JA (1995) Climatic warming and the decline of zooplankton in the California Current. Science 267:1324-1326

Sissenwine MP (1984) Why do fish populations vary? In: May $\mathrm{R}$ (ed) Exploitation of marine communities. SpringerVerlag, Berlin, p 59-94

Smith PE (1978) Biological effects of ocean variability: time and space scales of biological response. Rapp Cons Int Explor Mer 173:117-127

Smith PE (1990) Monitoring interannual changes in spawning area of Pacific sardine (Sardinops sagax). CalCOFI Rep 31:145-151

Smith PE, Lasker R (1978) Position of larval fish in an ecosystem. Rapp Cons Int Explor Mer 173:77-84

Smith PE, Lo NCH, Butler J (1992) Life-stage duration and survival parameters as related to interdecadal population variability in Pacific sardine. CalCOFI Rep 33:41-49

Theilacker GH, Huei Lo NCH, Townsend AW (1993) An immunochemical approach to quantifying predation by euphausiids on the early stages of anchovy. Mar Ecol Prog Ser 92:35-50

Verheye HM (2000) Decadal-scale trends across several marine trophic levels in the southern Benguela upwelling system off South Africa. Ambio 29:30-34

Submitted: June 15, 2006; Accepted: March 19, 2007

Proofs received from author(s): August 10, 2007 